Communications in Physics, Vol. 31, No. 3 (2021), pp. 321-327

DOI:10.15625/0868-3166/15809

\title{
EFFECT OF BIAS VOLTAGE AND CARRIER GAS ON THE HYDROGEN GAS-SENSING PROPERTIES OF TUNGSTEN OXIDE NANOBEADS
}

\author{
NGUYEN DUC HOA ${ }^{\dagger}$, DANG NGOC SON, DANG THI THANH LE, \\ NGUYEN THI THU HOA, CHU MANH HUNG AND NGUYEN VAN DUY \\ International Training Institute for Materials Science, \\ Hanoi University of Science and Technology, No.1 Dai Co Viet, Hanoi, Vietnam \\ E-mail: †ndhoa@itims.edu.vn; hoa.nguyenduc@hust.edu.vn
}

Received 30 December 2020

Accepted for publication 21 April 2021

Published 24 May 2021

\begin{abstract}
We investigated the effect of bias voltage and carrier gas on the hydrogen sensing performance of tungsten oxide nanobeads. The tungsten oxide nanobeads were prepared by a template-assisted method followed by calcination. The porous single walled carbon nanotube thin film was used as a sacrificed template for the deposition of tungsten, followed by thermal calcination at high temperature to oxidize $\mathrm{W}$ into $\mathrm{WO}_{3}$ and to burn out the template. The crystal structures and morphology of the synthesized materials were characterized by X-ray diffraction, field-emission scanning electron microscopy, high-resolution transmission electron microscopy and Raman spectra. Hydrogen gas sensing properties were tested in air and in $\mathrm{N}_{2}$ as reference for comparison. Our results indicated that Schottky junction was formed at the interface of $\mathrm{WO}_{3}$ and Pt electrodes. The sensor operated under reversed bias voltage could process excellent hydrogen sensing performance. In addition, the $\mathrm{H}_{2}$ sensing performance of the $\mathrm{WO}_{3}$ nanobeads is higher when measured in $\mathrm{N}_{2}$ gas as reference.
\end{abstract}

Keywords: $\mathrm{WO}_{3}$; nanobeads; $\mathrm{I}-\mathrm{V}$ characterization; $\mathrm{H}_{2}$ gas sensing properties.

Classification numbers: 07.07.Df.

\section{INTRODUCTION}

The presence of hydrogen in air at a concentration higher than the lower explosive limit can result in a catastrophic explosion [1]. For instance, during the 2011 Fukushima nuclear accident, three reactor buildings were damaged by hydrogen explosions. The explosive limits of hydrogen in air range from about $18-60 \%$ while the flammable limits are from $4-75 \%$ [2]. Development of low-cost and effective gas nanosensors for early detection and warning of hydrogen leakage is of crucial importance to prevent disastrous hydrogen explosion [3]. The self-assembly $\mathrm{SnO}_{2}$ C2021 Vietnam Academy of Science and Technology 
nanowires grown sensors have excellent performance in sensor response to hydrogen concentration in the range of 10 to $1000 \mathrm{ppm}$ [4]. Hydrogen gas sensor based on various $\mathrm{TiO}_{2}$ materials were summarized and commented [5]. Li et al reported a high-performance hydrogen gas sensor based on a hybrid of carbon nanotubes and conducting polymer [6]. Highly sensitive and selective gas sensor was realized using mesoporous materials [7]. The p-n heterojunction was reported to strongly enhance the gas sensing performance of metal oxides [8]. Hydrogen gas sensor is very important in alarming hydrogen leak because this gas can become flammable and explosive if its concentration in air is higher than 4\% [9]. Many studies focused on synthesis of different materials for hydrogen gas sensors $[10,11]$. Most sensor tests were performed in air as reference/carrier [12, 13]. Our recent study pointed out that the gas sensor based on $\mathrm{TiO}_{2}$ exhibited superior sensitivity to hydrogen gas when measured in $\mathrm{N}_{2}$ as reference [14]. However, the sensor showed relatively slow response and recovery speeds. Anyhow, it is obvious that the hydrogen gas sensing performance of metal oxide is strongly dependent on the carrier gases. However, none of the study report on the influence of reference gases on the hydrogen sensing performance of $\mathrm{WO}_{3}$.

Herein, we studied the effect of bias voltage and reference/carrier gas on the hydrogen gas sensing properties of $\mathrm{WO}_{3}$ nanobeads. The $\mathrm{WO}_{3}$ nanobeads were prepared by a template-assisted method. Dry air and nitrogen were used as reference/carrier for testing the calibrated $\mathrm{H}_{2}$ concentration. Results pointed out that the sensor measured in $\mathrm{N}_{2}$ as reference showed higher sensitivity to that measured in dry air. We also clarified the gas sensing mechanism of the fabricated sensor.

\section{EXPERIMENT}

In this study, $\mathrm{WO}_{3}$ nanobeads were prepared by using a template-assisted method, as reported elsewhere [15]. Typical synthesis includes (i) growing porous SWNTs as templates; (ii) depositing tungsten; and (iii) oxidizing tungsten in air. After deposition of Pt electrodes, the porous thick film of SWCNTs was grown by arc discharge method [16]. Then, $100 \mathrm{~nm}$ tungsten was sputtered over the porous SWCNT film, followed by thermal oxidation at $600^{\circ} \mathrm{C}$ for $2 \mathrm{~h}$ in air. The synthesized materials were characterized by a field emission scanning electron microscopy (SEM, JSM-7000F, Japan) and transmission electron microscopy (TEM, JEM-2100F, Japan). The X-ray diffraction (XRD) measurements were carried out by using $\mathrm{CuK} \alpha$-X-radiation (Model: D/max2500, Rigaku, Japan) to study the crystal structure and the formation of synthesized materials. The Raman spectra were collected under ambient conditions using the $514.5 \mathrm{~nm}$ line of an argon-ion laser. The electrical and gas sensing properties were measured by using a Keithley model 2400. Details about the gas sensing system can be found in Ref. [16]. The I-V curve was measured after aging the sensor at temperature of $400^{\circ} \mathrm{C}$ for $2 \mathrm{~h}$, then the bias voltage was swept from $-10 \mathrm{~V}$ to $10 \mathrm{~V}$ with an interval of $0.5 \mathrm{~V}$. The gas sensing measurement was done by switching on/off the hydrogen gas, while the resistance of the sensor was recorded as a function of time.

\section{RESULTS AND DISCUSSION}

Morphology and composition of the synthesized materials were studied by SEM image and EDS analysis, and the data are shown in Fig. 1. The SEM image demonstrates that the synthesized material has a bead-like morphology, where the nanobeads link together to form a porous nanowire film. The average size of nanobeads is approximately $100 \mathrm{~nm}$. Inset of Fig. 1(A) is a photo of 
the fabricated sensor, which includes two comb-type Pt electrodes and a thick sensing layer film. EDS analysis (Fig. 1(B)) presents the signal of $\mathrm{Si}, \mathrm{C}, \mathrm{O}$, and $\mathrm{W}$ elements. The original of $\mathrm{Si}$ and $\mathrm{Pt}$ is from the substrate and electrodes, whereas $\mathrm{W}$ and $\mathrm{O}$ are from the synthesized material. The presence of $\mathrm{C}$ is possibly due to the remaining SWCNTs, and hydrocarbon contamination. Atomic composition of material is $\mathrm{C}: \mathrm{O}: \mathrm{Si}: \mathrm{W}: \mathrm{Pt}=16.68: 37.74: 21.60: 11.77: 12.21$. The atomic ratio of $[\mathrm{O}] /[\mathrm{W}]$ is 3.43, indicating that the small content of $\mathrm{O}$ binds with $\mathrm{Si}$ in $\mathrm{SiO}_{2}$.
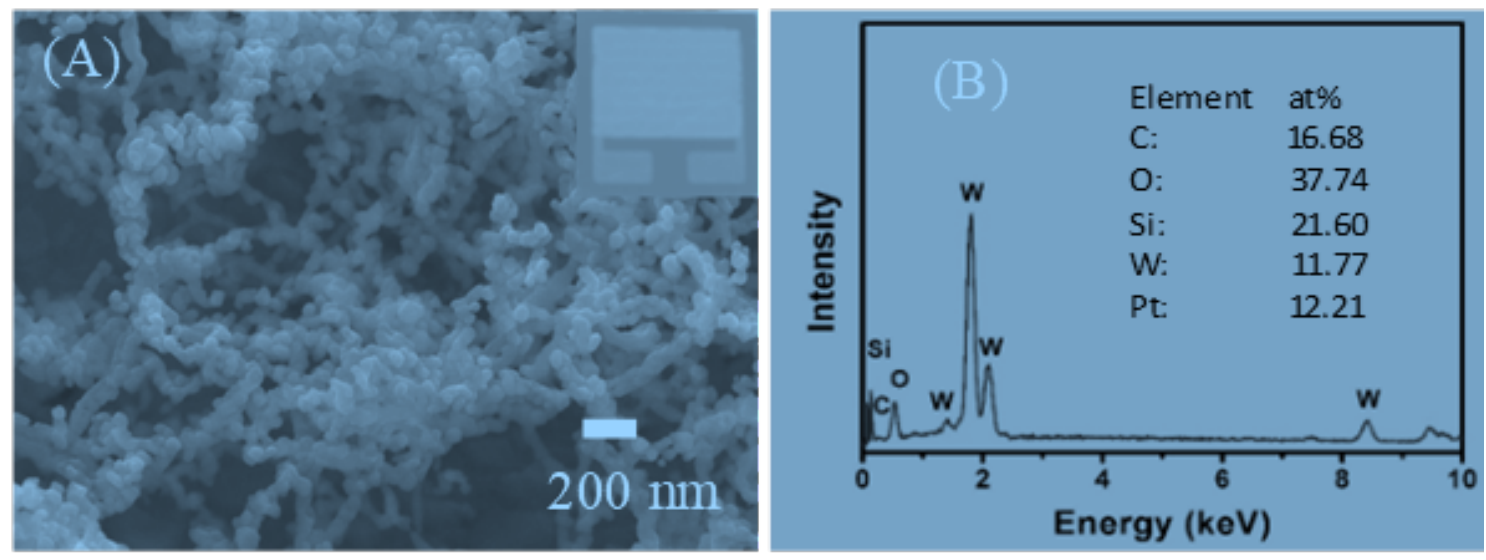

Fig. 1. (A) SEM image and (B) EDS analysis of the $\mathrm{WO}_{3}$ nanobeads.
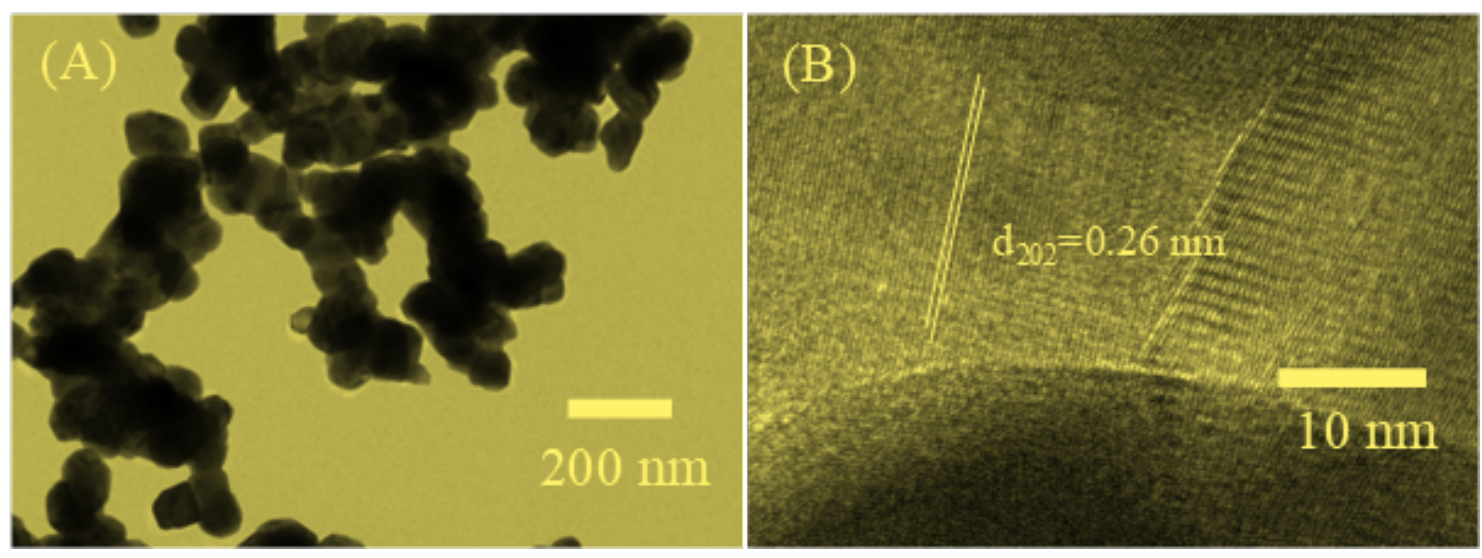

Fig. 2. (A) Low and (B) high magnification TEM images of the $\mathrm{WO}_{3}$ nanobeads.

TEM images of the synthesized $\mathrm{WO}_{3}$ nanobeads are shown in Fig. 2. The TEM image (Fig. 2(A)) reveals the bead-like structure of the material, where the average diameter of nanobeads is about $100 \mathrm{~nm}$. No SWCNT can be seen in the TEM indicating that the carbon was burnt out during calcination. The HRTEM image showed clear lattice fringes of the nanobeads. The gap between lattice fringes is $0.26 \mathrm{~nm}$, corresponding to the interspace of (202) planes of monoclinic 
$\mathrm{WO}_{3}$ [15]. The grain boundary between nanobeads is very clear because of the different orientation of each bead. The presence of grain boundaries can increase the response of the gas sensor because of the formation of the barrier height between nanobeads, which strongly depend on the ambient gases.

Crystal structure and characteristics of the synthesized materials were studied by XRD and Raman spectra, as shown in Fig. 3. The XRD pattern (Fig. 3(A) shows typical diffraction peaks of single phase monoclinic $\mathrm{WO}_{3}$ (JCPDS file no. 43-1035). Three strong peaks (001), (020), and (200) overlap due to the nanocrystal structure of the synthesized $\mathrm{WO}_{3}$ nanobeads. The Raman spectrum of the $\mathrm{WO}_{3}$ nanobeads exhibits typical strong peaks of monoclinic $\mathrm{WO}_{3}$. The peaks at $131 \mathrm{~cm}^{-1}$ and $274 \mathrm{~cm}_{-1}$ belong to $\mathrm{W}-\mathrm{O}-\mathrm{W}$ and $\mathrm{O}-\mathrm{W}-\mathrm{O}$ bending modes, respectively whereas peaks at 714 and $807 \mathrm{~cm}^{-1}$ belong to $\mathrm{W}-\mathrm{O}$ stretching modes of monoclinic $\mathrm{WO}_{3}$ nanocrystals [17]. No active mode of SWNT was observed indicating the total removal of template after calcination. Note that EDS analysis (Fig. 1) shows that the content of $\mathrm{C}$ is large of 16.68 at.\%, but TEM image and Raman spectrum did not show the signal of SWCTs, thus we assumed that the $\mathrm{C}$ in the sample is mainly carbon contamination and amorphous carbon formed by the decomposition of SWNTs under heat treatment.
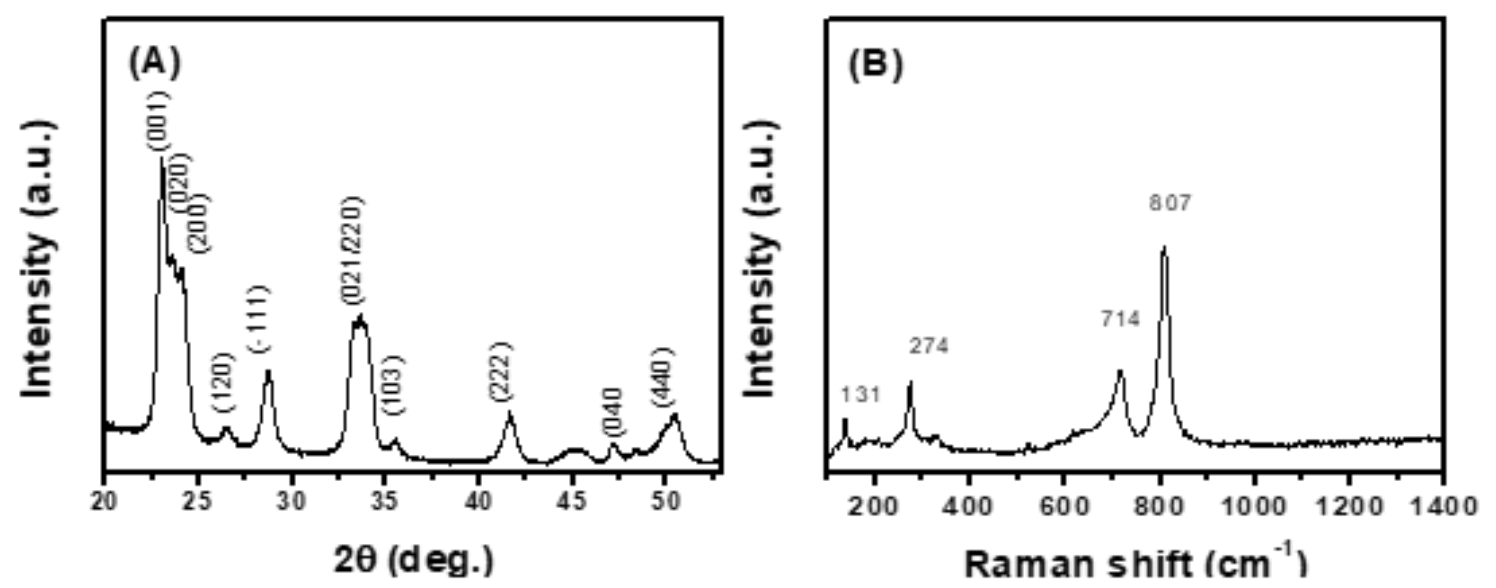

Fig. 3. (A) XRD pattern and (B) Raman spectrum of the $\mathrm{WO}_{3}$ nanobeads.

Electrical properties of the fabricated sensor were studied by I-V measurement at temperature of $200^{\circ} \mathrm{C}$ in air as shown in Fig. 4(A). The I-V curve shows a non-linear characteristic demonstrating the formation of Schottky contact between $\mathrm{WO}_{3}$ nanobead and Pt electrodes. It was expected that a perfect device with symmetrical I-V curve as the behavior of two diodes connected in opposite directions could be obtained in the $\mathrm{Pt} / \mathrm{WO}_{3} / \mathrm{Pt}$ structure. However, in our study, the non-symmetrical I-V data was obtained with a rectifying behavior in the negative bias voltage (reversed bias). The results are consistent with that of the single $\mathrm{WO}_{3}$ nanowire $\mathrm{Au} / \mathrm{WO}_{3} / \mathrm{Au}$ Schottky device, where the non-symmetrical I-V behaviors were explained by the drifting of oxygen vacancies in $\mathrm{WO}_{3}$ nanowire near the electrode during I-V measurement [18]. 
In addition, no breaking effect occurred under the reversed bias up to $10 \mathrm{~V}$. This is because in our study, the $\mathrm{WO}_{3}$ layer is a mat of nanobeads with many interconnects between nanobeads, thus when applied a voltage between two Pt electrodes, most of the voltage dropped at the contacts among nanobeads, and the real voltage applied at the interface between $\mathrm{Pt}$ and $\mathrm{WO}_{3}$ was much less than the measured values. Note that our study is consistent with the result in $\mathrm{Au} / \mathrm{WO}_{3} / \mathrm{Au}$ device based on single $\mathrm{WO}_{3}$ nanowire, despite the less difference in work function between $\mathrm{Au}(5.47 \mathrm{eV})$ and $\mathrm{WO}_{3}$ $(5.01 \mathrm{eV})$ of about $0.46 \mathrm{eV}$, where no breaking effect was occurred with the bias voltage up to $5 \mathrm{~V}$ [18]. Nevertheless, thanks to the nonsymmetry of the $\mathrm{Pt}-\mathrm{WO}_{3}$ contact in our study, we could fabricate a highly sensitive gas sensor when operated under reversed bias, as discussed later. By applying a voltage of $-2 \mathrm{~V}$, the transient resistance versus time of the sensor shows almost no change upon exposure to $6 \% \mathrm{H}_{2}$ (Fig. 4(B)). However, the sensor shows significantly high response value when applying a voltage of $2 \mathrm{~V}$ (Fig. 4(C)). This result indicates that the sensor is highly sensitive to $\mathrm{H}_{2}$ gas under reversed bias voltage. The sensor resistance decreases rapidly upon exposure to $\mathrm{H}_{2}$ with the response time of the sensor is about $15 \mathrm{sec}$. The sensor showed good recovery in which the sensor resistance recovered to the initial value after stop flowing $\mathrm{H}_{2}$ gas and exposure to air. The results indicate that our sensor works properly under reversed bias voltage.

Similarly, we tested the hydrogen sensing properties of the sensor under reversed bias voltage but changing the reference/carrier gas. As shown in Fig. 5, the sensor shows better response characteristics when using $\mathrm{N}_{2}$ as reference. The response value of 535 was obtained when testing to $6 \% \mathrm{H}_{2}$ gas using $\mathrm{N}_{2}$ as reference. This value is about 11 times higher than that measured using air as reference. However, the sensor resistance could not recover to the initial value after stopping exposure to $\mathrm{H}_{2}$ for $20 \mathrm{~min}$.
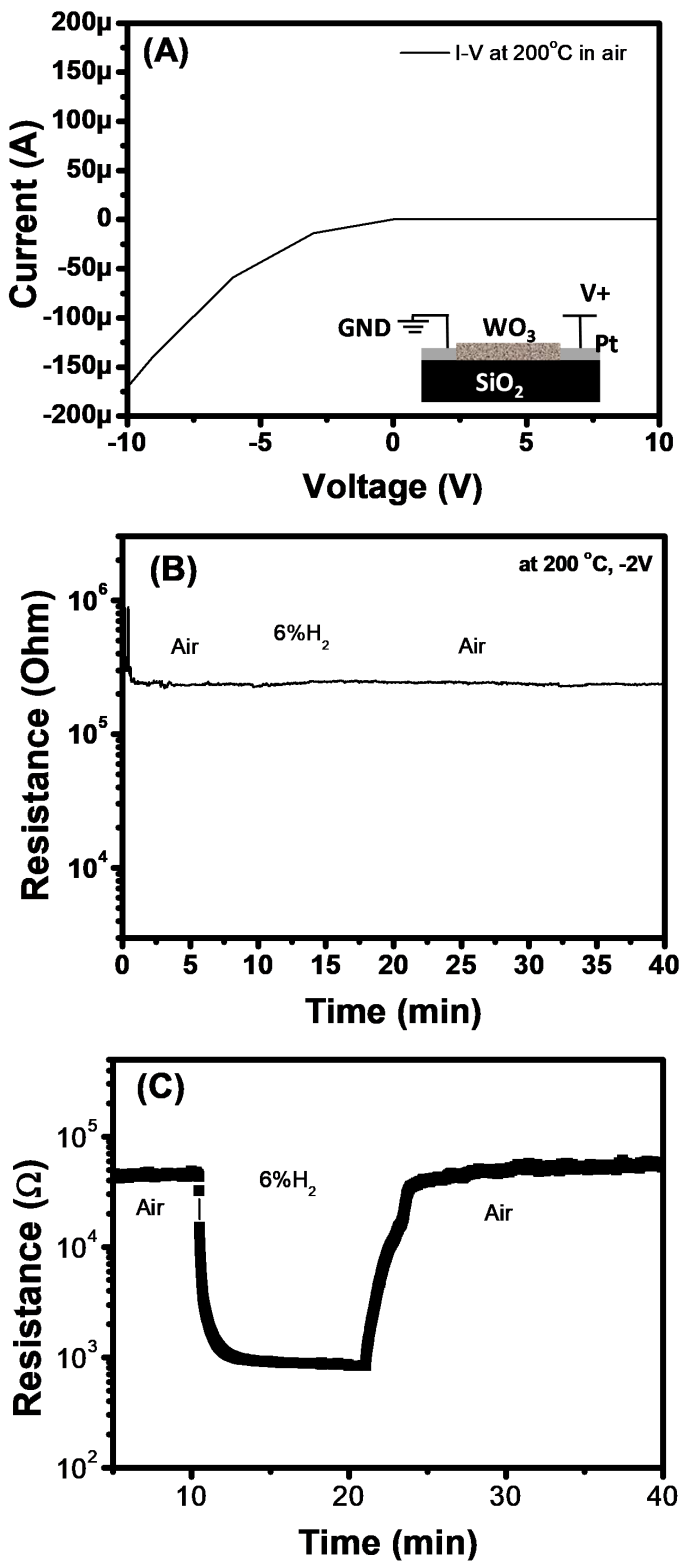

Fig. 4. (A) I-V curve; transient resistance versus time of the sensor upon exposure to $6 \% \mathrm{H}_{2}$ at $200^{\circ} \mathrm{C}$ under (B) forward and (C) reversed bias voltage. Inset (A) is electrode configuration of the device during I-V measurement. 
Gas sensing mechanism of the fabricated sensor is mainly determined by i) the surface reaction of hydrogen with preabsorbed oxygen species $\left(\mathrm{O}^{2-}, \mathrm{O}^{-}, \mathrm{O}^{2-}\right.$ on the surface of $\mathrm{WO}_{3}$, and ii) the reaction with the heterojunction between $\mathrm{WO}_{3}$ and Pt electrodes [19]. In our study, the surface reaction with preabsorbed oxygen species on the surface of $\mathrm{WO}_{3}$ is not dominant, because when tested under the forward bias the sensor showed ignorable response. Therefore, we assumed that the gas sensing properties of the fabricated sensor were mainly determined by the reaction with the Pt- $\mathrm{WO}_{3}$ heterojunction. Herein, the electrical properties and gas sensing performance of the $\mathrm{WO}_{3}$ nanobeads based sensor can be understood by realizing the formation of Schottky contact between n-type $\mathrm{WO}_{3}$ and Pt electrodes. The work function of $\mathrm{WO}_{3}$ is about $5.01 \mathrm{eV}$, which is lower than that of $\mathrm{Pt}(5.6 \mathrm{eV})$, thus when deposited on Pt the Schottky barrier is formed at the interface between Pt electrode and $\mathrm{WO}_{3}$ nanobeads. Upon exposure to $\mathrm{H}_{2}$ gas, the $\mathrm{H}_{2}$ is dissociated into active $\mathrm{H}$ atoms and those atoms react with $\mathrm{Pt}$ to form platinum hydride $\left(\mathrm{Pt}-\mathrm{H}_{\mathrm{x}}\right)$ with a lower work function, thus lowering the barrier height between $\mathrm{Pt}$ and $\mathrm{WO}_{3}$, thus decreases the sensor resistance [20].

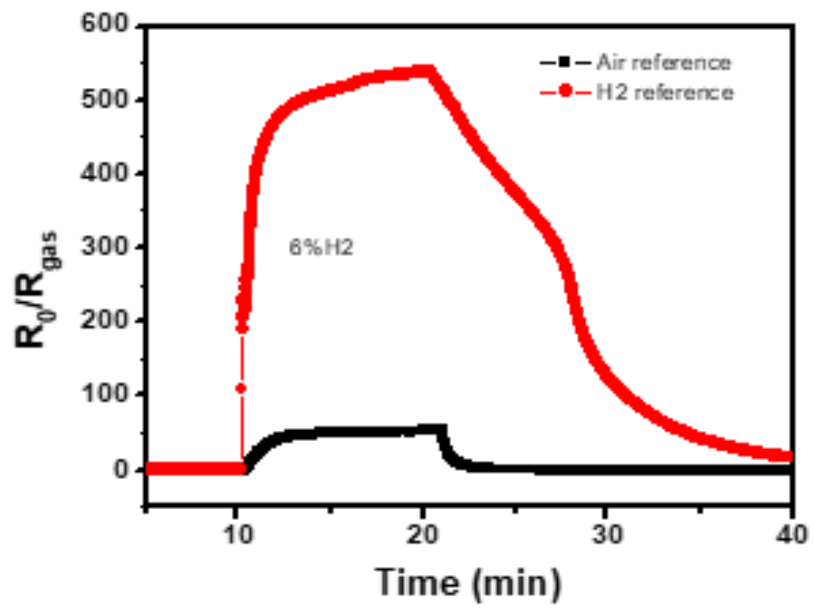

Fig. 5. Transient resistance versus time of the sensor upon exposure to $6 \% \mathrm{H}_{2}$ at $300^{\circ} \mathrm{C}$ under reversed bias voltage using air and $\mathrm{N}_{2}$ as references.

In addition to the reaction with $\mathrm{Pt}$ to form $\mathrm{Pt}-\mathrm{Hx}$, the active $\mathrm{H}$ atom can react with $\mathrm{WO}_{3}$ to form $\mathrm{HxWO}_{3}$, as reported in Ref. [21]. The released electrons decreased the electron depletion region on the surface of $\mathrm{WO}_{3}$, and thus the barrier height between $\mathrm{Pt}$ and $\mathrm{WO}_{3}$. As a result, the sensor resistance decreased upon exposure to hydrogen gas significantly because the $\mathrm{Pt}-\mathrm{WO}_{3}$ Schottky sensor could change from "close" to "open". In case of measuring in air as reference, oxygen gas reacts with Pt-Hx and $\mathrm{HxWO}_{3}$ and accelerates the releasing of hydrogen atoms. As a result, the response of the sensor measured in air is lower than that measured in $\mathrm{N}_{2}$ [22]. Furthermore, the sensor measured in air has a faster recovery time because of the acceleration reaction between oxygen with $\mathrm{Pt}-\mathrm{Hx}$ and $\mathrm{HxWO}_{3}$ to release $\mathrm{H}$ out of $\mathrm{Pt}-\mathrm{Hx}$ and $\mathrm{HxWO}$ to form $\mathrm{Pt}$, and $\mathrm{WO}_{3}$. 


\section{CONCLUSION}

We have reported our study about the effects of bias voltage as well as carrier gases on the hydrogen gas sensing properties of $\mathrm{WO}_{3}$ nanobeads. The high crystal $\mathrm{WO}_{3}$ nanobeads were synthesized by a template-assisted method followed by calcination. Gas sensing characterization demonstrated that under the forward bias, the sensor did not respond to $\mathrm{H}_{2}$, but it showed very high response under reversed bias voltage. In addition, the sensor measuring in $\mathrm{N}_{2}$ as reference exhibited superior response value compared to mearing in air reference.

\section{ACKNOWLEDGMENTS}

This work was financially supported by the Vietnam National Foundation for Science and Technology (NAFOSTED) under Grant No. 103.02-2020.18

\section{REFERENCES}

[1] S.M. Kim, H.J. Kim, H.J. Jung, J. Park, T.J. Seok, Y. Choa, T. J. Park and S. W. Lee, Adv. Funct. Mater. (2018) 1807760; doi:10.1002/adfm.201807760.

[2] V. Schröder, B. Emonts, H. Jan $\beta$ en and H.-P. Schulze, Chem. Eng. Technol. 27 (2004) 847.

[3] N. Van Duy, N.D. Hoa, N. Van Hieu, Sensors Actuators B Chem. 173 (2012) 211.

[4] B. Wang, L.F. Zhu, Y.H. Yang, N.S. Xu and G. W. Yang, J. Phys. Chem. C. 112 (2008) 6643.

[5] Z. Li, Z. Yao, A. A. Haidry, T. Plecenik, L. Xie, L. Sun and Q. Fatima, Int. J. Hydrogen Energy. 43 (2018) 21114.

[6] W. Li, N. D. Hoa and D. Kim, Sensors Actuators B Chem. 149 (2010) 184.

[7] N. D. Hoa and S. A. El-Safty, Anal. Methods 3 (2011) 1948.

[8] N. Van Hieu, P. Thi Hong Van, L. Tien Nhan, N. Van Duy and N. Duc Hoa, Appl. Phys. Lett. 101 (2012) 253106.

[9] S. Mohd Chachuli, M. Hamidon, M. Mamat, M. Ertugrul and N. Abdullah, Sensors 18 (2018) 2483.

[10] A. Mirzaei, H.R. Yousefi, F. Falsafi, M. Bonyani, J.-H. Lee, J.-H. Kim, H. W. Kim and S. S. Kim, Int. J. Hydrogen Energy 44 (2019) 20552.

[11] J.-H. Kim, A. Mirzaei, H. Woo Kim and S. S. Kim, Sensors Actuators B Chem. 284 (2019) 628.

[12] K. Yan, Y. Toku, Y. Ju, Int. J. Hydrogen Energy. 44 (2019) 6344.

[13] Y. Kim, Y.S. Choi, S.Y. Park, T. Kim, S.-P. Hong, T.H. Lee, C.W. Moon, J.-H. Lee, D. Lee, B. H. Hong and H. W. Jang, Nanoscale 11 (2019) 2966.

[14] N.D. Hoa, V. Van Quang, D. Kim and N. Van Hieu, J. Alloys Compd. 549 (2013) 260.

[15] N. Van Hieu, V. Van Quang, N. D. Hoa and D. Kim, Curr. Appl. Phys. 11 (2011) 657.

[16] N.D. Hoa, N. Van Quy, Y. Cho and D. Kim, Sensors Actuators B Chem. 135 (2009) 656.

[17] D.Y. Lu, J. Chen, J. Zhou, S.Z. Deng, N.S. Xu and J. B. Xu, J. Raman Spectrosc. 38 (2007) 176.

[18] J. Guo, Y. Zhou, H. Yuan, D. Zhao, Y. Yin, K. Hai, Y. Peng, W. Zhou and D. Tang, AIP Adv. 3 (2013) 42137.

[19] M. Horprathum, T. Srichaiyaperk, B. Samransuksamer, A. Wisitsoraat, P. Eiamchai, S. Limwichean, C. Chananonnawathorn, K. Aiempanakit, N. Nuntawong, V. Patthanasettakul, C. Oros, S. Porntheeraphat, P. Songsiriritthigul, H. Nakajima, A. Tuantranont and P. Chindaudom, ACS Appl. Mater. Interfaces 6 (2014) 22051.

[20] T. Scheler, O. Degtyareva, M. Marqués, C. L. Guillaume, J. E. Proctor, S. Evans and E. Gregoryanz, Phys. Rev. B. 83 (2011) 214106.

[21] R. Ab Kadir, W. Zhang, Y. Wang, J. Z. Ou, W. Wlodarski, A. P. O’Mullane, G. Bryant, M. Taylor and K. Kalantar-zadeh, J. Mater. Chem. A 3 (2015) 7994.

[22] K. Tsukada, H. Inoue, F. Katayama, K. Sakai and T. Kiwa, Jpn. J. Appl. Phys. 51 (2012) 15701. 